\title{
Erratum to: Effect of varying dietary energy levels during the last trimester of pregnancy on subsequent first lactation performance in Sahiwal heifers
}

Muhammad Fiaz • Muhammad Abdullah • Muhammad Nasir • Khalid Javed • Masroor Ellahi Babar • Talat Naseer Pasha • Makhdoom Abdul Jabbar

Published online: 17 December 2013

(C) Springer Science+Business Media Dordrecht 2013

Erratum to: Trop Anim Health Prod

DOI 10.1007/s11250-011-9998-7

There was an error in Table 4

The correct Table 4 is:

\begin{tabular}{lll}
\hline Parameters & ME 88\% & ME $100 \%$ \\
\hline Milk yield (Kg/day) & $4.20 \pm 0.07^{\mathrm{c}}$ & $5.87 \pm 0.06^{\mathrm{a}}$ \\
FCM (Kg/day) & $4.22 \pm 0.06^{\mathrm{c}}$ & $6.26 \pm 0.06^{\mathrm{a}}$ \\
\hline
\end{tabular}

The online version of the original article can be found at http://dx.doi.org/ 10.1007/s11250-011-9998-7.

M. Fiaz $\cdot$ M. Abdullah $\cdot$ K. Javed

Department of Livestock Production, University of Veterinary and

Animal Sciences, Lahore, Punjab, Pakistan

M. E. Babar

Institute of Biochemistry and Biotechnology, University of

Veterinary and Animal Sciences, Lahore, Punjab, Pakistan

M. Nasir $(\triangle) \cdot$ T. N. Pasha $\cdot$ M. A. Jabbar

Department of Food and Nutrition, University of Veterinary and

Animal Sciences, Lahore, Punjab, Pakistan

e-mail: nasir@uvas.edu.pk 